\title{
JOGOS E BRINCADEIRAS COMO RECURSO PEDAGÓGICO
}

\author{
Benedita Araújo dos Santos ${ }^{1}$ \\ Joicy Laura da Silva Agripino ${ }^{2}$ \\ Mara Rosemary Claviso Silveira ${ }^{3}$ \\ Marília Gomes da Silva ${ }^{4}$ \\ Patrícia Zabotto Ferreira ${ }^{5}$ \\ Zenaide Soares da Silva ${ }^{6}$
}

RESUMO: O educador precisa usar uma variedade de instumentos de ensino para transmissão e desenvolvimento do conhecimento dos educandos. Os jogos e brincadeiras representam um rico recurso educacional que inclui informação, cultura, comprovação de direitos, desenvolve a educação, entre outros benefícios e vantagens para aprender e contribuir para o desenvolvimento da criança e de suas potencialidades, além de construir relações cognitivas que privilegiem o carinho, o respeito, a solidariedade e o companheirismo. $\mathrm{Na}$ educação, o conhecimento é uma construção que ocorre dia-a-dia, o ato de brincar e aprender formam uma relação estabelecida no processo de adquirir conhecimento. $\mathrm{O}$ jogo é um dos recursos educacionais mais usados na motivação e promoção da aprendizagem, especialmente na educação de crianças.

Palavras-chave: Educador. Educando. Jogos. Brincadeiras.

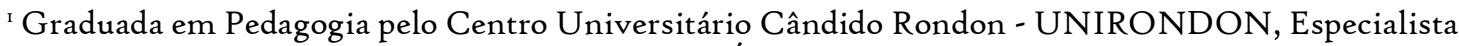
em Educação Infantil e Especial pelas Faculdades Águas Emendadas - FAE.

${ }^{2}$ Graduada em Pedagogia pela Universidade Federal de Maro Grosso - UFMT, Especialista em Educação Infantil e Anos Iniciais pelo Centro Universitário Leonardo da Vinci - UNIASSELVI.

3 Graduada em Pedagogia pelas Faculdades Integradas Mato-grossense de Ciências Sociais e Humanas, Especialista em Educação Infantil com ênfase em Educação Especial pelas Faculdades Integradas de Cuiabá - FIC.

${ }^{4}$ Graduada em Pedagogia pela Universidade Norte do Paraná - UNOPAR, Especialista em Docência da Educação Infantil pela Universidade Federal de Mato Grosso - UFMT.

${ }^{5}$ Graduada em Pedagogia pelo Centro Universitário de Maringá - UNICESUMAR, Especialista em Educação Infantil e Anos Iniciais do Ensino Fundamental pelo Centro Universitário de Maringá UNICESUMAR

${ }^{6}$ Graduada em Pedagogia pelo Instituto Cuiabano de Educação - ICE, Especialista em Educação Infantil pela Faculdade Afirmativo.
} 
ABSTRACT: The educator needs to use a variety of teaching instruments to transmit and develop the knowledge of the students. Games and games represent a rich educational resource that includes information, culture, proof of rights, develops education, among other benefits and advantages to learn and contribute to the development of children and their potential, in addition to building cognitive relationships that privilege the affection, respect, solidarity and companionship. In education, knowledge is a construction that occurs day by day, the act of playing and learning form a relationship established in the process of acquiring knowledge. The game is one of the most used educational resources in the motivation and promotion of learning, especially in the education of children.

Keywords: Educator. Teaching. Games. jokes.

\section{INTRODUÇÃO}

A educação lúdica é um ato da criança, mas também em qualquer idade, com significado, em todas as fases. Lúdico designa e define tudo relacionado ao brincar ou jogar. Relacionado à educação, o jogo assume o papel de fonte de materiais pedagógicos auxiliando o processo de ensinoaprendizagem e facilitando a assimilação dos conteúdos.

O professor constrói seu próprio conhecimento, com características diferentes em cada fase, é preciso destacá-los, pois se tornam recursos direcionadores de sua própria prática pedagógica. Desse modo um dos objetivos de qualquer bom profissional está em ser cada vez mais competente em seu trabalho. Em geral se obtém esta melhora profissional através do conhecimento e a experiência: o conhecimento das vairáveis que atuam na práica e a experiência para utilizá-las. $O$ conhecimento, aquele que resulta da investigação, das experiências dos outros e de modelos, 
exmplos e propostas (ZABALA, 2014).

As contribuições dos jogos e brincadeiras na aquisição do conhecimento a partir do seu uso no ensino-aprendizagem são grandes, especialmente nas séries iniciais, e sua eficácia e eficiência ainda são debatidas no ambiente escolar. Assim, tem se definido como tema deste artigo a importância dos jogos e brincadeiras na educação infantil.

As crianças vivenciam o mundo do brincar logo nos primeiros anos de vida, identificam os tipos de jogos a partir dos mais simples e passam a dedicar-se aos jogos, adquirindo, respeitando e participando em regras e regras que são propostas. Jogos e brincadeiras tornam-se recursos lúdicos que a maioria dos professores usam para motivação e/ou facilitação da aprendizagem dos alunos.

No processo educacional da criança, o professor deve estar ciente da importância do significado do brincar infantil e valor do brincar para a aprendizagem e o desenvolvimento do aluno. Os jogos e brincadeiras fazem parte do mundo infantil, as crianças nos primeiros anos de vida já identificam os mais diversos tipos, partindo dos mais simples e depois dedicando-se ao jogo, adquirindo regras de respeito, socialização, participação e entendimento. e, fazendo com que seu aprendizado se torne mais divertido e interessante.

Entretanto, percebemos que as crianças estão cada vez cedo no ambiente escolar e que o processo de alfabetização mais precoce e, portanto, o brincar acaba perdendo espaço como recurso pedagógico e lúdico na escola. 


\section{DESENVOLVIMENTO}

\section{I Breve histórico de jogos e brincadeiras}

Com o passar do tempo, várias ideias sobre jogos surgiram. Para alguns, os jogos representavam uma forma de fazer com que as crianças gastassem mais energia e lhes dassem paz de espírito. Para outros, representava o potencial de preparar uma criança para a vida e despertar equilíbrio.

As escolas tradicionais organizam os jogos. Referindo-se à história dos jogos, Almeida (200o, p. 16) diz que: "nos séculos XVI e XVII, as escolas foram fundadas pelos jesuítas, seguindo o modelo de escola tradicional com rígida formação moral [...]”.

No período da Era Cristã, os jogos, tinham um caráter disciplinador,

não existindo meios para a expansão dos jogos, considerados maléficos pela sociedade cristã. Para Chicon (2004, p. 2I): "proibia a recreação às crianças na tentativa de preservá- las do mal, ou seja, ao recrear-se, a criança estaria desagradando a Deus”. Já no período Renascentista, os jogos e brincadeiras ganharam mais espaços.

Brougeré (apud) Kishimoto (2005, p. 24) diz que as novas tendências pedagógicas concebem o jogo algo natural do ser humano. $O$ jogo é tão antigo quanto a própria cultura.

Os jogos podem ser usados para ampliar e estimular o desenvolvimento lógico dos alunos. Ele permite que se estabeleça, conclua e desenvolva o aprendizado de uma maneira divertida e interessante.

De acordo com Maluf (2008, p. II): “As atividades lúdicas, juntament com a boa pretenção dos educadores, sã caminhos que contribuem para o bem-esar e 
entretenimnto das crianças, garantindo-lhes uma agadável estadia na crehce ou escola”.

O rigor metódico é um dos requisitos do ensino, pois se pretende dotar os alunos de um método de aprendizagem crítico que aproxime os alunos das teorias que conduzem ao conhecimento a inculcar neles, sendo indiscutível a curiosidade e a reprovação dos alunos a esse conhecimento.

Os jogos são ferramentas que favorecem o desenvolvimento do ser humano. E através deles, segundo Macedo (2007, p. 14): “O brincar é agradável por si mesmo, aqui e agora. Na perspectiva da criança, brinca-se pelo prazer de brincar, e não porque suas consequências sejam eventualmente positivas ou preparadoras de alguma outra coisa".

De acordo com Brenelli (2003, p. 136) os jogos "evoluíram e chegaram até os meios modernos de comunicação como computadores e Internet, o jogar é uma brincadeira organizada, convencional, com papéis e posições marcadas", cujo processo de evolução apresenta características bem específicas. No século XIX, os educadores se interessar pelo estudo dos jogos infantis. Final do século XIX e começo do século XX, enfatizaram a importância de se preservar os costumes infantis e as coleções lúdicas eram tratadas como relíquias.

No entanto, o jogo possui características comuns a todas as culturas devido ao contínuo transbordamento ou unidade física do pensamento humano e ao conservadorismo de todas as pessoas, porém, existe o perigo de transformar essas coleções de jogos em documentos mortos. Apresente seu filho ao grupo social brincando em grupo, iniciando o processo de socialização da criança (BRENELLI, 2003).

Para Brenelli (2003) na década de I930 a I950 a socialização da criança 
se dá por meio de brincadeiras que envolvem a criança, o professor e outras crianças. No processo de socialização, as crianças interagem com outras crianças, acostumam-se a ver os pontos de vista de outras crianças, o que estimulará o pensamento. Essa troca leva à construção do desenvolvimento.

No período de 1920 à 1960, o jogo era usado como cenário para estudar outras atividades. A observação espontânea das brincadeiras por meio de diários de brincadeiras, de fotografias e anotações para documentar o comportamento de crianças e adultos, foi alcançado por meio de inovações metodológicas.

Nas décadas de 1950 a 1970 destaca-se a importância da comunicação no jogo, distinguindo suas mensagens, regras, normas, respeito e percepção da importância da ordem.

O jogar é o brincar dentro de um conjunto de regras e com um objetivo predeterminado. Almeida (2000, p. 22) diz que: "o ato consiste em uma atividade livre, conscientemente tomada como não séria e exterior à vida habitual, mas ao mesmo tempo capaz de absorver o jogador de maneira intensa e total".

O professor deve saber a idade e ajudar a criança a usar o brinquedo até que ela possa brincar sozinha. Os professores também devem participar de jogos, mostrar diversão e incentivar a participação.

Para Kishimoto (2005, p. I8): “o jogo é para a criança um fim em si mesmo, ele deve ser para nós um meio (de educar), de onde seu nome jogo educativo - que torna cada vez mais um lugar na linguagem da pedagogia maternal”.

Para professores e alunos, são ferramentas de formação, criando um 
ambiente favorável à investigação e à busca de soluções.

De acordo com Kishimoto (2005) na educação, ela se dá justamente pelo caráter sério que é a aquisição do conhecimento, e pelo caráter não sério que dá espaço para a ludicidade, dando liberdade de ação à criança.

\subsection{Classificação dos jogos}

Para Rizzi \& Haidt (200I, p. 175) o jogo: "é uma atividade física ou mental organizada por um sistema de regras e lúdica, pois se joga pelo simples prazer de realizar esse tipo de atividade. Jogar é uma atividade natural do ser humano".

Segundo Militão (200o, p. 24): “o jogo é um processo de vivência. É uma técnica uma dinâmica, uma competição saudável entre pessoas" e ainda pode ser concebido como um conjunto de peças para brincar; passatempo divertido que segue certas regras; o estilo de jogar em uma competição; competições ou séries de competições são caracterizadas por exercícios e competições para aumentar o prêmio.

Para Friedman (1996, p. 28) em relação à classificação dos jogos, diz que: "Piaget descreveu, classificou e explicou o jogo nas diferentes fases de desenvolvimento da criança" e se classificam da seguinte maneira:

a) Jogos de exercício sensório-motor: é o primeiro a aparecer na vida das crianças, relaciona-se com atividade de prazer funcional e não de representação, coloca em ação comportamentos sem modificar suas estruturas, exercita-as pelo próprio prazer que encontra em seu funcionamento.

b) Jogos simbólicos: entre a idade de dois e seis anos, representam a diferenciação entre significantes e significados. São ficção ou imitação 
quando se transforma objetos ou no desempenho de papéis. Assinala a realidade. Em conformidade com Araújo (200o, p. 63), as características do jogo simbólico são: "liberdade total de regras; desenvolvimento da imaginação e da fantasia; ausência de objetivo; ausência de uma lógica". Cada tipo de jogo tem uma importância na aprendizagem em função dos seus objetivos e finalidades.

c) Jogos de construção: para Kishimoto (2005, p. 40): “os jogos de construção são considerados importantes, porque enriquecem a experiência sensorial, estimula a criatividade e o desenvolvimento das habilidades da criança". Exploram e manipulam objetos, observando suas características e funcionalidade.

d) Jogos de regras: surgem entre a idade de quatro a sete anos e vai até os doze. Para Araújo (200o, p. 64): “[...] ao jogar de regras, as crianças assimilam a necessidade de cumprimento das leis da sociedade e das leis da vida" e as regras podem ser:

a) Regras transmitidas: presentes nos jogos que se tornam institucionalizados, diferentes realidades sociais se impõem por pressão de sucessivas gerações (jogo de bolinha de gude);

b) Regras espontâneas: são jogos de regras de natureza contratual e momentânea.

Os jogos de regras, de acordo com Araújo (200o, p. 67) originam da socialização "dos jogos de exercício simples ou dos jogos simbólicos e de uma socialização que comporta tanto relações entre indivíduos mais novos e indivíduos mais velhos como relações entre indivíduos de uma mesma geração".

São combinações sensório-motoras ou intelectuais, proporciona a 
competição entre os indivíduos, fazendo com que a regra seja necessária. Em relação ao brinquedo educativo, segundo Kishimoto (2005, p. 37): “ao assumir a função lúdica e educativa, o brinquedo, dentro do contexto educacional assume função lúdica, porque propicia diversão, prazer e até mesmo desprazer".

O brinquedo tem uma função educativa, quando o professor ensina algo que orienta a criança em seu saber, seus conhecimentos e sua apreensão do mundo. Existem várias etapas pelas quais as crianças devem passar para entender o segredo do brincar e usá-lo bem, especialmente em jogos em grupo. É normal que a criança, ao brincar em grupo, queira voltar a brincar sozinha ou apenas na presença de amigos, mas sozinha.

Placco (2002, p. I45) afirma que: “[...] um local como a escola poderia, com facilidade, incorporar esses desenvolvimentos que mencionamos, ainda para as possibilidades interdisciplinares dos jogos”.

[...] podemos supor que uma possível agressividade pudesse ser percebida, canalizada, analisada e superada, se o dirigente da cena for um educador, ou alguém sensível para permitir a discussão de uma situação desagradável e indesejada (PLACCO, 2002, p. 86).

Através dos brinquedos e materiais concretos ou pedagógicos são estimuladas as primeiras conversas, a troca de ideias, contatos com parceiros, imaginário infantil, exploração e a descoberta de relações.

\subsection{Aprendizagem através dos brinquedos e brincadeiras}

Por meio dos jogos, as crianças têm o primeiro contato com objetos, pessoas e o mundo ao seu redor. Há uma série de concepções teóricas muito diferentes sobre o uso de jogos no processo de ensino e aprendizagem dos alunos. 
A missão de uma boa educação infantil é possibilitar, por meio do brincar, do afeto e da sociabilidade, a voz dos sonhos das crianças. Acredita-se que através do uso de jogos pode-se popularizar e estimular o desenvolvimento lógico nos alunos, estabelecer relações, concluir e implementar conteúdos de aprendizagem de forma divertida e interessante.

A aprendizagem por meio do brincar tem maior probabilidade de envolvimento das crianças, e a escola é um dos locais onde as atividades lúdicas são desenvolvidas, com muitos benefícios para os alunos. Além disso, cada atividade tem seu próprio significado único para cada jogador. O lúdico apresenta funções sociais e mostra a representação que a sociedade tem da criança e as concepções que ela tem sobre a infância. A criança cresce com a brincadeira da criança e a brincadeira, paralelamente, cresce com o seu crescimento.

A brincadeira é uma fonte de prazer no dia-a-dia delas. Mas o brincar também tem outras importantes funções no desenvolvimento infantil, como por exemplo, contribuir com seu desenvolvimento físico e cognitivo.

O indivíduo tende a um equilíbrio, que está relacionado a um comportamento adaptativo em relação à natureza, que por sua vez sugere um sujeito de características biológicas inegáveis, as quais são fonte de construção da inteligência. $O$ desenvolvimento e caracterizado por um processo de sucessivas equilibrações. O desenvolvimento psíquico começa quando nascemos e segue até a maturidade, sendo comparável ao crescimento orgânico: com este, orienta-se, essencialmente, para o equilíbrio (PIAGET, 1974, p. 13).

De acordo com Machado (20oI, p. 37) o brincar é: “[...] um grande canal para o aprendizado, senão o único canal para verdadeiros processos 
cognitivos". A associação da educação com a prática e o uso de jogos e brincadeiras no processo de ensino e aprendizagem não é novidade. Os jogos são importantes para o desenvolvimento das crianças, sua inteligência e personalidade e, portanto, são a base para o desenvolvimento humano integral.

O lúdico é um adjetivo que designa e define tudo o que se relaciona com brincar ou brincar e é principalmente para entender que a criança é feita para brincar. Com as atividades lúdicas, as crianças ganham experiência, pois o brincar é uma parte tão importante de suas vidas e, ao mesmo tempo, elas se desenvolvem por meio de suas próprias brincadeiras e intervenções lúdicas realizadas por outras crianças, realizadas por outras crianças e adultos (KISHIMOTO, 2005).

O brincar na escola não é o mesmo que brincar em outras ocasiões, pois a vida na escola é regida por normas que regem as ações e interações das pessoas entre si e, naturalmente, essas normas estão presentes nas atividades das crianças.

Para Vygotsky (apud) Wajskop (1995, p. 16) a brincadeira infantil é: "entendida como atividade social da criança, de natureza e origem específicas, elementos fundamentais para a construção de sua personalidade e compreensão da realidade na qual se insere".

A brincadeira é essencialmente um espaço de aprendizagem sociocultural localizado no tempo e no espaço. A escola não é um lugar como os outros lugares, onde a criança aprende a se relacionar com seu próprio conhecimento.

Para Aguiar (1998, p. 43) o jogo: "e facilita tanto o progresso da personalidade integral da criança como o progresso de cada uma de suas 
funções psicológicas, intelectuais e morais”.

As brincadeiras e os jogos têm uma especificidade quando ocorrem na escola, pois são mediadas pelas normas institucionais. Kishimoto (2005, p. 33) afirma que as atividades lúdicas contribuem para "o desenvolvimento intelectual da criança sugerindo o uso de atividades motoras na forma de jogos para dominar conceitos e desenvolver certas habilidades psicológicas" como memória, avaliação e resolução de problemas.

O jogo chega à escola para facilitar a assimilação da aprendizagem, para que ela se torne mais significativa e concreta. Sobre a intervenção dos jogos no desenvolvimento infantil, direcionado ao processo de aprendizagem da criança. Brincar não deve ser visto como qualquer atividade, brincar constrói o caráter da criança.

A brincadeira é uma atividade psicológica de grande complexidade, é uma atividade lúdica que desencadeia o uso da imaginação criadora pela impossibilidade de satisfação imediata de desejos por parte da criança. A brincadeira enriquece a identidade da criança, porque ela experimenta outra forma de ser e de pensar; amplia suas concepções sobre as coisas e as pessoas, porque o faz desempenhar vários papéis sociais ao representar diferentes personagens (CARVALHO E PONTES, 2003, p.48).

Para Pozas (2012, p. 7): "Brincar é uma das principais atividades da criança. É por meio da brincandeira que ela revive a realidade, constrói significados e os ressigfica momentos depois. Dessa forma, aprende, cria e se desenvolve em todos os aspectos".

Em geral, as crianças não aprendem da mesma maneira ou na mesma velocidade. No entanto, enquanto brincam, aprendem a trabalhar com suas emoções, medos e sob a pressão da realidade externa.

[...] para progredir a criança precisa ser respeitada e sentir-se ouvida. Para que também aprenda a ouvir, a criança precisa antes de ser ouvida [...] mas sem ser atropelada. Presença e 
disponibilidade por parte do adulto constroem o laço afetivo, mas é preciso ter claro que cada brincadeira é uma busca; uma interferência direta pode impedir que a criança faça suas descobertas e domine dificuldades (MACHADO, 2001, p. 25).

Kishimoto (2005, p. 38) afirma que: "ao utilizar de modo metafórico a forma lúdica para estimular a construção do conhecimento, o brinquedo educativo conquistou o espaço definitivo na educação infantil”, o lúdico peças têm uma relação direta com a criança. A criança brinca para conhecer a si mesma e aos outros em suas relações mútuas, para aprender normas sociais de comportamento, para interagir, para se integrar à sociedade.

Conforme com Kishimoto (2005, p. 20): “o brinquedo é um suporte da brincadeira. A diferença entre jogo e brinquedo supõe uma relação íntima com a criança, ou seja, a ausência de um sistema de regras que organizam sua utilização".

Os educadores e psicólogos concordam que os jogos e brincadeiras infantis são atividades físicas e mentais que promovem o desenvolvimento pessoal como sociabilidade, integralidade e harmonia.

Os brinquedos estão associados à cultura porque contêm características culturais específicas da sociedade. Os jogos escolares visam facilitar o aprendizado do aluno para que seja mais assimilado, significativo e concreto.

\section{CONCLUSÃO}

O brincar é imprescindível no processo ensino-aprendizagem, o brincar, o jogar e o uso de brinquedos favorecem o desenvolvimento dos aspectos emocionais, afetivos, cognitivos e sociais dos alunos. 
As brincadeiras e jogos perderam espaço para a alfabetização precoce, sendo que pais e escolas cobram muito do professor para que seu filho saia da educação infantil e não perceba o quanto isso é prejudicial para a criança.

A atitude de esforçar uma criança de cinco anos a manusear facilmente a letra cursiva é bastante complexo, pois suas habilidades motoras ainda não estão preparadas para essa exigência. Ao mesmo tempo, a pressão de leitura dessas crianças não é adequada para sua idade.

Porém, na instituição esses requisitos são normais e aqueles que não os atendem estão fora do padrão esperado. A importância da alegria, dos jogos e das brincadeiras na educação infantil e como esses recursos são utilizados pelos educadores em sala de aula fazem toda a diferença.

Os jogos e atividades lúdicas e em todas as demais atividades lúdicas são uma ferramenta muito valiosa para a prática pedagógica da educação infantil, pois através dessas atividades devemos ser incluídos e inseridos nos conteúdos de forma lúdica, diferente e muito ativa e engajada. entre os alunos para que possam aprender e brincar ao mesmo tempo.

Diante das mudanças ocorridas na educação e na concepção de crianças, escolas e professores ainda estão despreparados para acolher e acomodar esse novo perfil de alunos no período pré-escolar.

A utilização de jogos como fonte de apoio pedagógico e de apoio à intervenção exige dos educadores um maior comprometimento com o conteúdo estudado, que deve ser significativo e sensível para a criança, crianças e professores.

\section{REFERÊNCIAS}

AGUIAR, J.S. Jogos para o ensino de conceitos. Campinas: Papirus, 1998. 
ALMEIDA, P.N. Educação Lúdica. São Paulo: Loyola, 2000.

ARAÚJO, Iracema Rezende de Oliveira. A utilização de Lúdicos para Auxiliar a Aprendizagem e Desmistificar o Ensino da Matemática. 2000. 137 f. Dissertação (Mestrado em Engenharia da Produção). Programa de Pós Graduação em Engenharia da Produção da Universidade Federal de Santa Catarina. Disponível em https://core.ac.uk/display/30359688. Acesso em 04/Io/202I.

BRENELLI, Rosely Palermo. O jogo como espaço para pensar: a construção de noções lógicas e aritméticas. São Paulo: Editora Papirus, 4⿳a edição, 2003.

CARVALHO, A. M. A.; PONTES, F. A. R. Brincadeira é cultura. In: A.M.A. Carvalho; C.M.C. Magalhães, F. A. R. Pontes; I. D. Bichara (Orgs.). Brincadeira e cultura: viajando pelo Brasil que brinca.(pp.15-30). São Paulo: Casa do Psicólogo, 2003.

CHICON, José Francisco. Jogo, mediação pedagógica e inclusão: a práxis pedagógica. Vitória: EDUFES, 2004.

KISHIMOTO, Tizuko Morchida .Jogo, brincadeira e a educação. 8.ed. São Paulo: Cortez, 2005.

MACHADO, Marina M. O brinquedo-sucata e a criança: a importância do brincar, atividades e materiais. $4^{\underline{a}}$ ed., São Paulo, SP: Loyola, 200 .

MALUF, Angela Cristina Munhoz. Atividades lúdicas para educação infntil: conceitos, orientações e práticas. Editora Vozes, Petrópolis, 2008.

MACEDO, Lino de. Os jogos e o lúdico na aprendizagem escolar [recurso eletrônico] Dados eletrônicos. Porto Alegre: Artmed, 2007.

MILITÃO, Albigenor. Jogos, Dinâmicas e Vivências Grupais. Rio de Janeiro: Qualitymark, 200o.

POZAS, Denise. Criança que brinca mais aprende mais: a importância da atividade lúdica para o desenvolvimento. Editora Senac: Rio de Janeiro, 2012.

PIAGET, J. Aprendizagem e conhecimento. Rio de Janeiro: Freitas Bastos, 1974 . 
PLACCO, V. Jogos lúdicos. Revista do professor. v. 24. n. 70, 2002.

RIZZI, Leonor; HAYDT, Regina Célia C. Atividades lúdicas na educação da criança. São Paulo: Editora Ática, 200ı.

WAJSKOP, Gisela. Brincar na pré-escola. São Paulo: Cortez, 1995.

ZABALA, Antoni. A prática educativa: como ensinar [recurso eletrônico]. Porto Alegre: Penso, 2014. 